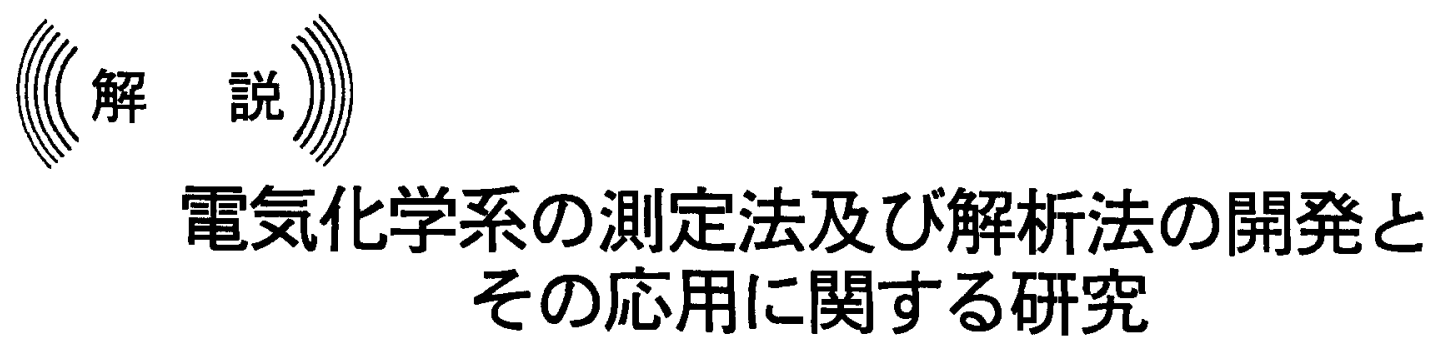

1 はじめに

近年，走查トンネル顕微鏡（STM）を始めとする種々 の走查プローブ法とよばれる表面測定法及びさまざまな 分光法あるいは水晶振動子微量天秤（QCM）を電気化 学測定に併用することによって，電極の表面の姿ばかり でなく，反応過程についてあ分子・原子レベルでの知見 が得られるようになってきた．しかしながら，電気化学 測定における基本は，作用電極の電位（または電気化学 セルの電圧）とセルを流れる電流のいずれかを独立変数 として制御したときもう一方の変数である電流または 電位の応答を測定し，その結果の解析に基づいて，熱力 学, 速度論, 反応機構などに関するデー夕を得ることに なる．同様に STM，分光法，QCM などの出力データ あ制御変数である電位または電流の関数であることは勿 論である。

電極反応は不均一反応であるので，電荷移動過程とと もに，反応に関与する物質の電極界面への補給あるいは 界面からの除去という物質移動過程, さらに電荷移動に 付随して起こる化学反応や吸着過程などを伴う。またそ のため, 電気化学セル内に招ける電荷移動過程と物質移 動過程及びその他の諸過程・諸特性を適切に考虑した電 流一電位曲線，電流一時間曲線あるいは電位一時間曲線 などの理論式の導出と，測定結果の解析から必要なデー 夕を抽出する方法の確立が必要とされる。

これらの問題は原理的には次のようにして解くことが できる ${ }^{1)}$. 電気化学セル内の物質移動は, 各化学種につ いての物質移動方程式，セル内での電位分布についての Poisson 式，および流速についての Navier-Stokes の 式と連続の式によって規定され，これらの方程式は，実 験条件に応じた適切な初期条件之境界条件を用いて解か れる.さらに, 電流密度, 電極電位および電極表面にお ける濃度との関係を表わす式（例えば Butler-Volmer 式）を用いて，電流一電位曲線の式などが求められるこ とになる。

東京工業大学大学院総合理工学研究科（开226 横浜市緑区長津 田町 4259)

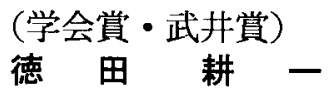

実際には上述のような複雜な形のまま直接に解くこと は困難であり，実験条件を適切に選抧することによって， 多くの方程式を簡単な形にして扱うことになる，流速な ども流体力学で既に求められていればその結果を利用す ればよいのであって，よほど特殊な問題を除いては Navier-Stokes の式を解くことはほとんど必要ない.

これまで, 対流ボルタンメトリー, 電極表面の不均一 性, 微小電極, 化学修飾電極, セル内の電位電流分布な どの問題を扱ってきたが，本稿ではぺージが限られてい るので, 対流ボルタンメトリーのうち, 回転円盤電極 （RDE）ボルタンメトリーに限って述べることにする。

\section{2 回転円盤軍極ボルタンメトリー}

\section{1 限界対流拡散電流}

回転する円盘による流速分布の問題はvon Kármán²) および Cochran ${ }^{3)}$ によって解かれ，Levich ${ }^{4)}$ はその結 果を用いて RDEに扔ける物質移動を取り扱った，十分 な支持電解質を含み溶液内の抵抗による電位分布の影響 などを考える必要がない場合には，RDEへの物質移動 は電極の場所によらず一様になり (uniform accessibility), 半径方向の依存性を考えなくてもよいので化 学種 B の物質移動方程式は

$$
\partial c_{\mathrm{B}} / \partial t=D_{\mathrm{B}} \partial^{2} c_{\mathrm{B}} / \partial z^{2}-\nu_{z} \partial c_{\mathrm{B}} / \partial z
$$

で表される，ここで $D_{\mathrm{B}}$ は B の拡散係数， $\nu_{z}$ は電極に垂 直な $z$ 軸方向の流速であり, 式

$$
\begin{aligned}
\nu_{\mathrm{z}}=-(\nu \omega)^{1 / 2}\left\{0.51023 \zeta^{2}-(1 / 3) \zeta^{3}\right. \\
+
\end{aligned}
$$

で与えられる．ただし， $\zeta=z(\omega / \nu)^{1 / 2}$ であり， $\omega$ は 電極の回転角速度, $\nu$ は溶液の動粘性率である，RDE の特徵は定常電流-電位曲線を測定できることにあり， 定常状態を扱う場合には始めから $\partial c_{\mathrm{B}} / \partial t=0$ として式 (1)を解けばよい，RDEでの B の限界対流拡散電流値 は Levich 式で表される。

$$
I_{\mathrm{d}}=0.620 n F A \nu^{-1 / 6} D_{\mathrm{B}}{ }^{2 / 3} \omega^{1 / 2}=n F A D_{\mathrm{B}} c_{\mathrm{B}}{ }^{0} / \delta
$$
ここで, $A=\pi r_{\mathrm{d}}{ }^{2}$ ( $r_{\mathrm{d}}$ は $\mathrm{RDE}$ の半径)， $c_{\mathrm{B}}{ }^{0}$ は B の溶 液内部での濃度， $\delta$ は拡散層の厚さである。 Levich 式 
では式 (2)の右辺第 1 項のみを考慮してしているので, $\delta$ は

$$
\delta_{\mathrm{L}}=1.61 D_{\mathrm{B}}^{\mathrm{L} / 3} \nu^{1 / 6} \omega^{-1 / 2}
$$

となるが，Newman ${ }^{5)}$ は式(2)の第 3 項までを考虑して $\delta_{\mathrm{N}}=1.610\left(1+0.2980 \mathrm{Sc}^{-1 / 3}+0.14514 \mathrm{Sc}^{-2 / 3}\right)$

$$
D_{\mathrm{B}}{ }^{1 / 3} \nu^{1 / 6} \omega^{-1 / 2}
$$

を求めた。ここで添字 L， N は式 (4) と（5）の表現の違 いを明示するためにつけたものであり， $S c=\nu / D_{\mathrm{B}}$ は シュミット数であるが, 通常の水溶液ではレ $\approx 10^{-2} \mathrm{~cm}^{2}$ $/ \mathrm{s}, D_{\mathrm{B}} \approx 10^{-5} \mathrm{~cm}^{2} / \mathrm{s}$ であるので $\mathrm{Sc}^{-1 / 3} \approx 0.1$ となる. この結果は Levich 式で計算した限界電流値は約 3\%ほ ど大きくなることを示しており，拡散係数の決定には式 (5)を用いる方がよいことが分かる.

\section{2 正弦対流変調法 (Sinusoidal Hydrodynamic}

\section{Modulation)}

RDE は通常一定の回転速度で用いられるが, Miller とBruckenstein ら ${ }^{6-8)}$ は回転数を時間の関数として制 御して, そのときの電流応答を測定する方法を考案した。

特に, 中心回転数 $\omega_{0}$ の周りで正弦関数として

$$
\begin{aligned}
& \omega^{1 / 2}=\omega_{0}^{1 / 2}(1+\varepsilon \sin \sigma t), \\
& \varepsilon=\Delta \omega^{1 / 2} / \omega_{0}^{1 / 2}
\end{aligned}
$$

のように変化させる方法は正弦対流変調 (SHM) と呼 ばれる。電流応答は

$$
I=I \omega_{0}+\Delta I \sin (\sigma t-\phi)
$$

のようになり，通常の RDEボルタンメトリーにおける 中心回転速度に対応する $I_{0}-$ 電位曲線に加えて, 変調 電流 $\Delta I$-電位曲線を交流ボルタンメトリーと同様な方法 で記録する， $\Delta I$ は対流拡散に関連する項のみが抽出さ れ, 電気二重層の充電電流, 表面反応過程の寄与が含ま れないという大きな利点をもつ. ところで, 変調電流 $\Delta$ Iについても Levich 式の関係が成り立つのは, 変調の 周波数 $\sigma$ が十分小さいときのみであって， $\sigma$ の增大と共 に比

$$
A=\left(\Delta I / \omega^{1 / 2}\right) /\left(I \omega_{0} / \omega_{0}^{1 / 2}\right)=\Delta I / \varepsilon I \omega_{0}
$$

の值は 1 から大きく減少し, また位相シフト $\phi$ は増大す ることが実験的に分かっており，この問題を理論的に扱っ た9). 円盤の回転が华定常状態值の近傍で時間によって変 化する場合の流速㖓の時間依存性については Sparrow と Gregg ${ }^{10)}$ によって扱われており，それを利用できた。 限界対流拡散電流についての振幅係数 $A$ および位相シ フト $\phi$ は, 変調の周波数と中心回転周波数の比 $p=\sigma /$ $\omega_{0}$ および Sc の関数として求まり, Fig. 1 上 2 に示す ように, 広い $S c$ の範囲で実験値と理論值との良い一致 が得られた ${ }^{9)}$.

電極反応速度を考慮した電流-電位曲線の取り扱いも 行った結果, いわゆる準可逆の電子移動反応過程の系で は電位に対する $A / A_{1}$ のプロットはFig. 3 に示すよう に極小値をもっことが明らかにな゙った。ここで $A_{1}$ は式
(9)に打いて $\Delta I$ および $I \omega_{0}$ が限界電流になったときの $A$ の值である．この曲線の解析から速度定数が決定できる. Fig. 4 は Fe (CN) ${ }_{6}{ }^{3-}$ の還元過程にこの方法を適用した 結果で， $A / A_{1}$ のプロットは明瞭な極小を示しており， 解析により $0.1 \mathrm{~cm} / \mathrm{s}$ の式量速度定数が求められた。

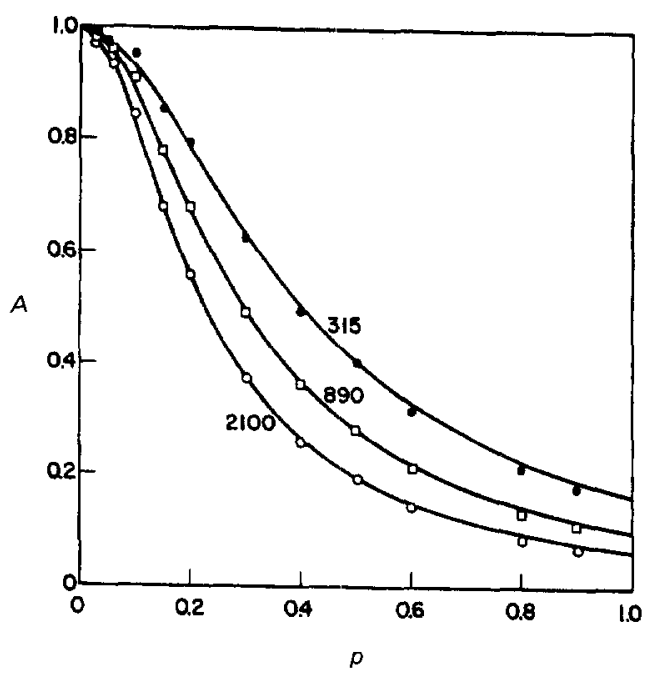

Fig. 1 Amplitude factor $A$ as a function of $p$ for Sc values of 315,890 , and 2100 , as marked. Solid lines are theoretical, points are experimental. (Reproduced by permission of The Electrochemical Society Inc.)

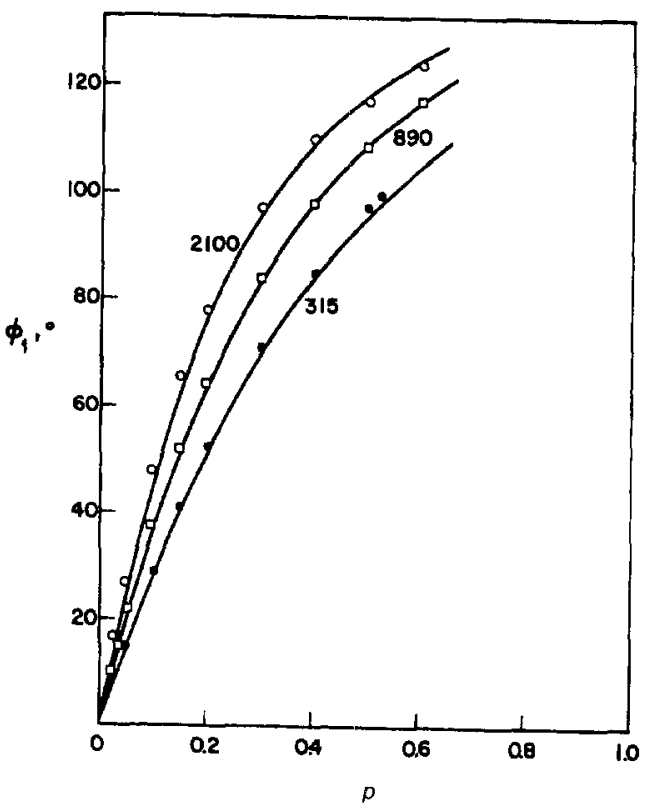

Fig. 2 Phase shift $\phi_{1}$ as a function of $p$ for $S c$ values of 315,890 , and $2100, S c$ values marked. Solid lines are theoretical, points are experimental values. (Reproduced by permission of The Electrochemical Society Inc.) 


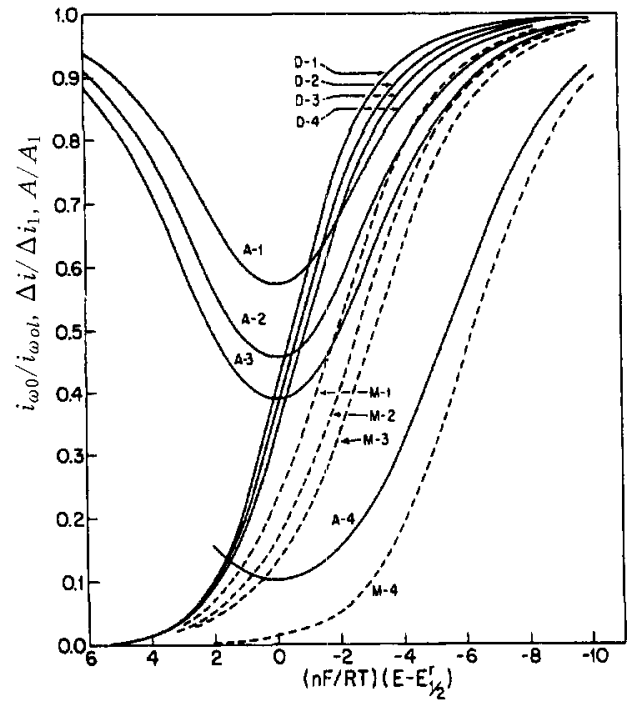

Fig. 3 Plot of normalized current functions vs. $(n F / R T)\left(E-E_{1 / 2}{ }^{r}\right) . \alpha=0.5, \mathrm{D}=5.12 \times 10^{-5} \mathrm{~cm}^{2} / \mathrm{s}$, $\nu=1.075 \times 10^{-2} \mathrm{~cm}^{2} / \mathrm{s}$, and $p=0.4$. Curves D 1 -D 4 are $i_{\omega 0} / i_{\omega o l}, \mathrm{M} 1-\mathrm{M} 4$ are $\Delta i / \Delta i_{1}$, and A $1-\mathrm{A} 4$ are $A / A_{1}$ plots. The values of $k_{0}(\mathrm{~cm} / \mathrm{s}), \omega_{0}(\mathrm{rpm})$, and $\sigma(\mathrm{rad} / \mathrm{s})$ are curve $1,1 \times 10^{-2}, 1500,20 \pi$; curve $2,5 \times 10^{-3}, 900,12 \pi$; curve $3,5 \times 10^{-3}, 1500,20 \pi$; curve $4,1 \times 10^{-3}, 1500,20 \pi$. (Reproduced by permission of The Electrochemical Society Inc.)

SHM は電極反応の速度論的解析以外に, $\mu \mathrm{M}(\mathrm{M}=$ mol $\mathrm{dm}^{-3}$ ) 以下の濃度の分析，抬散係数の測定，表面 過程と溶液内での過程の分離など様々の問題に適用して その特徽を利用できるが13)，従来はSHM 測定を行うた めには装置を自作せざるをえなかった，最近，装置が市 販されるようになり，今後㕕く利用されることが期待さ れる.

\subsection{RDE における非定常測定}

RDE は通常は定常状態での测定ができるところにそ の特長があるが, 電位ステップ法, 電位掃引ボルタンメ トリー, 定電流クロノポテンショメトリー, パルスボル タンメトリーなどの理論的取り扱いと実験への適用が行 われている14). 非定常での測定むいろいろ行われている. 我々は可逆 ${ }^{15)}$, 準可逆および非可逆過程 ${ }^{16)}$, および均一 化学反応が電極反応と組み合わさって存在する場合 ${ }^{17)}$ に ついて RDE での交流ボルタンメトリーの理論式を導出 した. RDEでの交流測定は直流成分が定常状態になる ので, 静止電極における测定とは異なり, 低周波数で屯 直流分極からの影響は少ない，しかしながら低周波数に おいては, 交流電位の摄動による拡散層と電極の回転に よる拡散層のカップリングが起こってくる，2500 rpm での電極回転速度においては, 交流周波数 $40 \mathrm{~Hz}$ 以上 で電極の回転の影響は完全に無視できることを明らかに

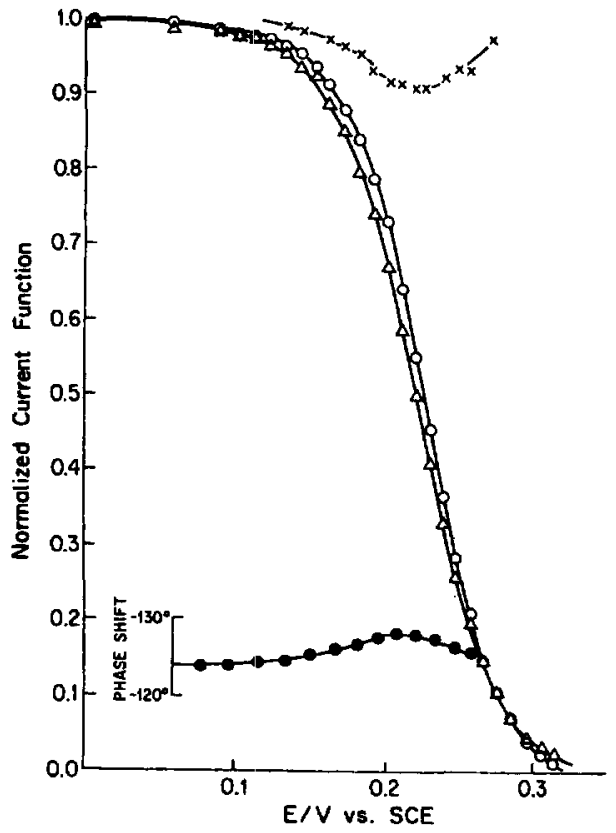

Fig. 4 Normalized current-potential curve $(-\mathrm{O}-)$, normalized modulated current-potential curve ($\triangle-), A / A_{1}(-\times-)$, and corresponding phase shift (-O) for reduction of $2 \mathrm{mM} \mathrm{Fe}(\mathrm{CN})_{6}{ }^{3-}$ in $0.4 \mathrm{M} \mathrm{K}_{2} \mathrm{SO}_{4}$. Electrode : platinum, $\omega_{0}=900 \mathrm{rpm}$, $\sigma=10 \mathrm{~Hz} \quad(p=0.67) . \Delta \omega^{1 / 2}=2 \mathrm{rpm}^{1 / 2}$. Tempera ture $25^{\circ} \mathrm{C}$. (Reproduced by permission of The Electrochemical Society Inc.)

した.

$\mathrm{RDE} の$ 非定常測定八の応用として，クロノクーロメ トリーの正確な理論式を与え, その結果を使って, 濃度 の分からない種の拡散係数を濃度とともに同時決定する 方法を確立することができた。もともとこの方法は Morris ${ }^{19)}$ によって提筷されたものであるが，そこで用 いられた式は雑であり，使用しにくいものであった．理 論式の導出には $\mathrm{Hale}^{2(1)}$ による変数変換

$$
\begin{aligned}
& \tau=D_{\mathrm{B}} t / \delta^{2}, x=\varphi / \delta, u=c_{\mathrm{B}} / c_{\mathrm{B}}{ }^{0} \\
& \varphi=\int_{0}^{z} \exp \left\{\int_{0}^{z}\left(W / D_{\mathrm{B}}\right) \mathrm{d} z\right\} \mathrm{d} z \\
& \delta=\int_{0}^{\infty} \exp \left\{\int_{0}^{2}\left(W / D_{\mathrm{B}}\right) \mathrm{d} z\right\} \mathrm{d} z
\end{aligned}
$$

を用いて，方程式(1)を

$\partial u / \partial \tau=(\mathrm{d} \varphi / \mathrm{d} z)^{2} \partial^{2} u / \partial x^{2}$

に変換し，流速の式(2)を用いて Crank-Nicholson 法 により解いた，電位を反応が起こっていない值から限界 電流值を与える電位までステップさせたときの電気量 $(Q)$-時間 $(t)$ 曲線は, Fig. 5 に示すように, 非定常な 電流がやがて定常電流值になると直線的に変化する。こ の直線部分は式 


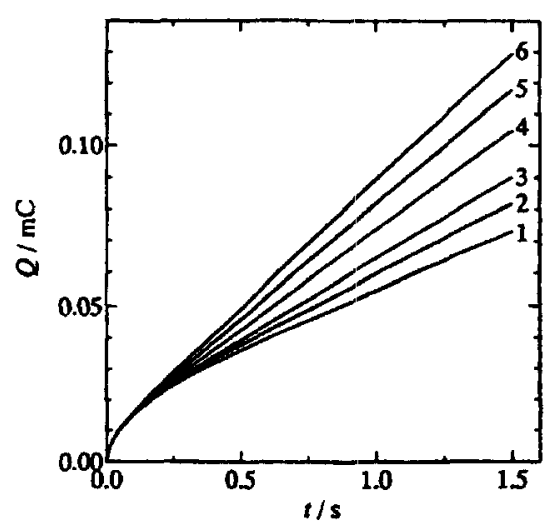

Fig. 5 Hydrodynamic chronocoulometric data for the oxidation of $\mathrm{Fe}(\mathrm{CN})_{6}{ }^{4-}$ to $\mathrm{Fe}(\mathrm{CN})_{6}{ }^{3-}$ at rotating GC disk electrode $(\phi=3 \mathrm{~mm})$ in aqueous solution containing $0.1 \mathrm{M} \mathrm{KCl}$ and $2.50 \mathrm{mM}$ $\mathrm{Fe}(\mathrm{CN})_{6}^{4-}$. Electrode rotation rate: (1) 200 , (2) 300 , (3) 400, (4) 600 , (5) 800 , and (6) $1000 \mathrm{rpm}$. The potential of the working electrode was stepped from 0.0 to $0.40 \mathrm{~V}$ vs. $\mathrm{Ag} / \mathrm{AgCl}$.

$$
Q=0.3764 n F A c_{\mathrm{B}}{ }^{0} \delta_{\mathrm{N}}+\left(n F A D_{\mathrm{B}} c_{\mathrm{B}}{ }^{0} / \delta_{\mathrm{N}}\right) t
$$
で表されることが求められた。この式は 50 から 3000 ま での範囲のSc 数に対して誤差 $0.3 \%$ 以内で成立する. 式 (14) 中の $\delta_{N}$ は式 (2)の第 3 項まで考慮しているので, 式(5)で与えられる. Fig. 5 のようなプロットの傾きと 切片の值から Sc を容易に決定できる.Scから搪散係数 を求めるには，溶液の動粘性率レの值は予め求めておく ことが必要である．反応の電子数 $n$ が分かっていれば, 溶液中の反应種の濃度が未知であっても求めることがで きる. 式(14)の妥当性は $0.1 \mathrm{M} \mathrm{KCl}$ 水溶液中の $\mathrm{Fe}(\mathrm{CN})_{6}{ }^{4-}$ に適用して確かめられた。ささらに，種々の溶媒中での酸 素の濃度と拡散係数の決定に用いることができた. 当然 ながら，この方法は，球電極や微小電極でのクロ/アン

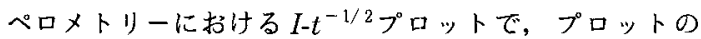
勾配と $t \rightarrow \infty$ における電流值の切片から二つの未知数を 同時に決定するの之同じ原理に基づいているが，種々の 電極材料を用いることができ，電極の形状と寸法を精度 良く決定できるという長所がある.

\section{4 化学修飾電極における反応機構の解析}

化学修飾電極における諸過程の速度論的解析には RDEが大きな役割を果たして来た. 特に電子移動メディ エイターによる反応過程の解析には Koutecky-Levich 式が用いられた，単なる電子移動ではなく，修飾された 分子亡反応基質との化学結合による中間体の生成を含 むような複雑な機構から成る系であっても，RDEでの
Levich プロットの適切な解析から, 反応機構と反応速 度定数の决定を行うことができることが明らかとなった。

\section{3 おりに}

はじめに述べたように新しい測定技術の展開により， 原子・分子レベルでの挙動が実験的に，次々と明らかに されてきている，が，それらの説明にはこれまでの現象 論的取り扱いだけではなく，分子論的あるいは統計力学 的な扱いを加えていく必要がある，また固体内の物質及 び電荷移動など，溶液と比較して複雑な系を扱う必要が 増してきていると思われる。これらの問題に取り組んで 行きたい.

\section{文献}

1) 松田博明, 電気化学, 34, 560 (1966).

2) Th. von Kärmán, Z.Angew. Math. Mech, 1, 233 (1921).

3) W. G. Cockran, Proc. Cambridge Phil.Soc., 30, 365 (1934).

4) V. G. Levich, Physicochemical Hydrodynamics, Prentice Hall, Englewood Cliffs, N. J. (1962).

5) J. Newman, J. Phys. Chem., 70, 1327 (1966).

6) B. Miller and S. Bruckenstein, J. Electrochem. Soc.,117, 1032 (1970).

7) B. Miller, M. I. Bellavance and S. Bruckenstein, Anal. Chem.,44, 1983 (1972).

8) B. Miller, M. I. Bellavance and S. Bruckenstein, J. Electrochem. Soc., 120, 1351 (1973).

9) K. Tokuda, S. Bruckenstein and B. Miller, J. Electrochem. Soc., 122, 1316 (1975).

10) E. M. Sparrow and J. L. Gregg, J. Aerospace Sci., 27, $252(1960)$.

11) K. Tokuda and S. Bruckenstein, J.Electrochem. Soc., 126, 431 (1979).

12) Y. Kanzaki and S. Bruckenstein, J. Electrochem. Soc., 126, 437 (1979)

13) S. Bruckerstein and B. Miller, Acc. Chem. Res., 10, 54 (1978).

14) C. M. A. Brett and A. M. C. F. Oliveira Brett, Comprehensive Chemical Kinetics, vol. 26 (Ed., C. H. Bamford and R.G.Compton), Elsevier, Chap. 5 (1986) and references cited therein.

15) K. Tokuda and H. Matsuda, J. Electroanal. Chem., 82, 157-171 (1977).

16) K. Tokuda and H. Matsuda, J. Electroanal. Chem., 90, 149-163 (1978).

17) K. Tokuda and H. Matsuda, J. Electroanal. Chem., 95, $147-157$ (1979).

18) M. Tsushima, K.Tokuda and T. Ohsaka, Anal. Chem., 66, 4551 (1994).

19) S. E. Morris, Trends Anal. Chem., 7, 227 (1988).

20) J. M. Hale, J. Electroanal. Chem., 6, 187 (1963) ; 8, 332 (1964)

21）岸岡真也, 大坂武男, 徳田耕一, 電気化学会第 64 回大会 講演要旨集 2 E 12 (1997). 